\title{
CARACTERIZAÇÃO DO POTENCIAL ARQUEOLÓGICO DO COMPLEXO ARQUEOLÓGICO DE PAULO AFONSO, BAHIA
}

\author{
Amanda Azevêdo Cavalcanti \\ Tavares*
}

Bruno de Azevêdo Cavalcanti
Tavares**

Maria Cleonice de Souza Vergne*** $^{* *}$

RESUMO: O registro rupestre sempre foi uma importante evidência de atividades de grupos humanos na pré-história. O Brasil, hoje, é considerado o país como a maior concentração de sítios com grafismos rupestres do mundo. Sendo assim, no Nordeste, há uma significativa presença de sítios com grafismos rupestres inseridos no complexo arqueológico de Paulo Afonso, localizado no município de Paulo Afonso, Bahia. O presente trabalho tem como objetivo principal, caracterizar o potencial arqueológico desta grande área arqueológica levando em consideração o contexto geoambiental da região. A análise da potencialidade arqueológica está pautada, metodologicamente, na revisão da literatura atual acerca nas principais pesquisas que estão sendo desenvolvidas no local, uma vez que a motivação primordial para este estudo concentra-se na escassez de pesquisas sobre a área de Paulo Afonso e na preservação do patrimônio arqueológico inserido neste complexo arqueológico. No geral, este estudo pretende gerar subsídios para futuras pesquisas que busquem preencher lacunas na discussão acerca do processo de ocupação humana pré-histórica nesta região do vale de São Francisco.

Palavras-chave: Registro rupestre; Potencial arqueológico; Patrimônio; Complexo Arqueológico de Paulo Afonso.

ABSTRACT: Rock art records have been an important evidence of human groups in Prehistory. Brazil, today, it's considered the country with the greater concentration of archaeological sites with rock art records in the whole world. Thus, in the Northeastern region, there is a significant recurrence of sites with rock art in the archaeological complex of Paulo Afonso, located in the municipality of Paulo Afonso, Bahia. This paper aims to characterize the archaeological potential take into account the geoenvironment context of the region. The archaeological potential analysis is settled methodologically, in the state of art of the mainly researches developed in that region, once that the primarily motivation for this study is concentrated in the lack of data over the Paulo Afonso area and the heritage archaeological preservation inserted in that archaeological complex. In general, the intention of this study is to generate subsides for futures researches to seek to fill the lack of discussion about the prehistoric human occupation process in the São Francisco valley.

Keywords: Rock Art; Archaeological Potential; Heritage; Paulo Afonso Archaeological Complex. 


\section{INTRODUÇÃO}

Pode-se afirmar que as pinturas rupestres são os primeiros registros de expressão da história da cultura humana. Assim, segundo Pessis (2003) a acumulação de conteúdos da cultura humana ao longo do processo de desenvolvimento cerebral, levou os grupos pré-históricos a elaborar novas formas de comunicação para além da tradição oral. Infelizmente, a compreensão dos significados desses traços rupestres foi intensamente afetada pelo fato das grandes mazelas que seus autores sofreram ao longo de anos e anos de colonização.

Atualmente, sabe-se que o Brasil tem o maior conjunto de pinturas rupestres do mundo. E na região Nordeste concentra-se uma significativa parte desses registros pré-históricos do que foi e do que ainda é uma das mais importantes formas de expressão cultural humana existente. Trata-se de remanescentes culturais de diferentes grupos étnicos, cujas histórias ainda são desconhecidas principalmente por não haver, como afirma Martin (2008), pesquisas suficientes que investiguem as filiações étnicas dos autores desses preciosos registros.

Assim, é certo que os grafismos rupestres são componentes importantíssimos dentro de um universo cultural étnico, pois constituem a possibilidade do desenvolvimento de saberes sobre esses povos indígenas que uma vez habitaram o Nordeste brasileiro, mais especificamente a região do vale de São Francisco que o foco da pesquisa.

Logo, o presente trabalho tem como objetivo principal analisar o potencial arqueológico do Complexo Arqueológico de Paulo Afonso", localizado no município de Paulo Afonso, Bahia. Atualmente, foram catalogados 64 sítios rupestres intactos e 48 sítios destruídos nesta área arqueológica (Figura 1).

Este trabalho será realizado com base na problemática de que a área pesquisada possui uma escassez de pesquisas e levantamentos aprofundados sobre os sítios rupestres lá situados, e por estes apresentarem peculiaridades de registro rupestre e localização, apontadas por Vergne e Marques (2009) quando comparados a outros sítios também localizados na região do vale e que já possuem um aprofundamento em pesquisa arqueológicas considerável.

As motivações do trabalho estão relacionadas à necessidade da preservação do patrimônio arqueológico da grande área arqueológica de Paulo Afonso, Bahia. Pois, com o atual processo destrutivo que sofrem tais sítios e pela escassez em pesquisas arqueológicas sobre este complexo arqueológico, é de vital importância conservá-los com o propósito de resguardar uma parte das evidências desses grupos humanos que lá viveram e como àquelas implicam na compreensão das lacunas históricas da região do vale do São Francisco.

${ }^{1}$ Caracteriza-se como complexo arqueológico por englobar algumas comunidades situadas no município de Paulo Afonso. São elas: Malhada Grande, Rio do Sal, Mão Direita e Lagoa das Pedras. 
É prudente ressaltar que o presente trabalho trata-se de uma pesquisa inicial, uma vez que, metodologicamente, está pautado numa revisão de literatura e levantamento bibliográficos de estudos mais recentes sobre a área que apresentam informações que apontam estado de conservação e caracterização dos sítios. Informações estas que são muito importantes para realizar uma análise dos parâmetros potencializadores do complexo arqueológico de Paulo Afonso.

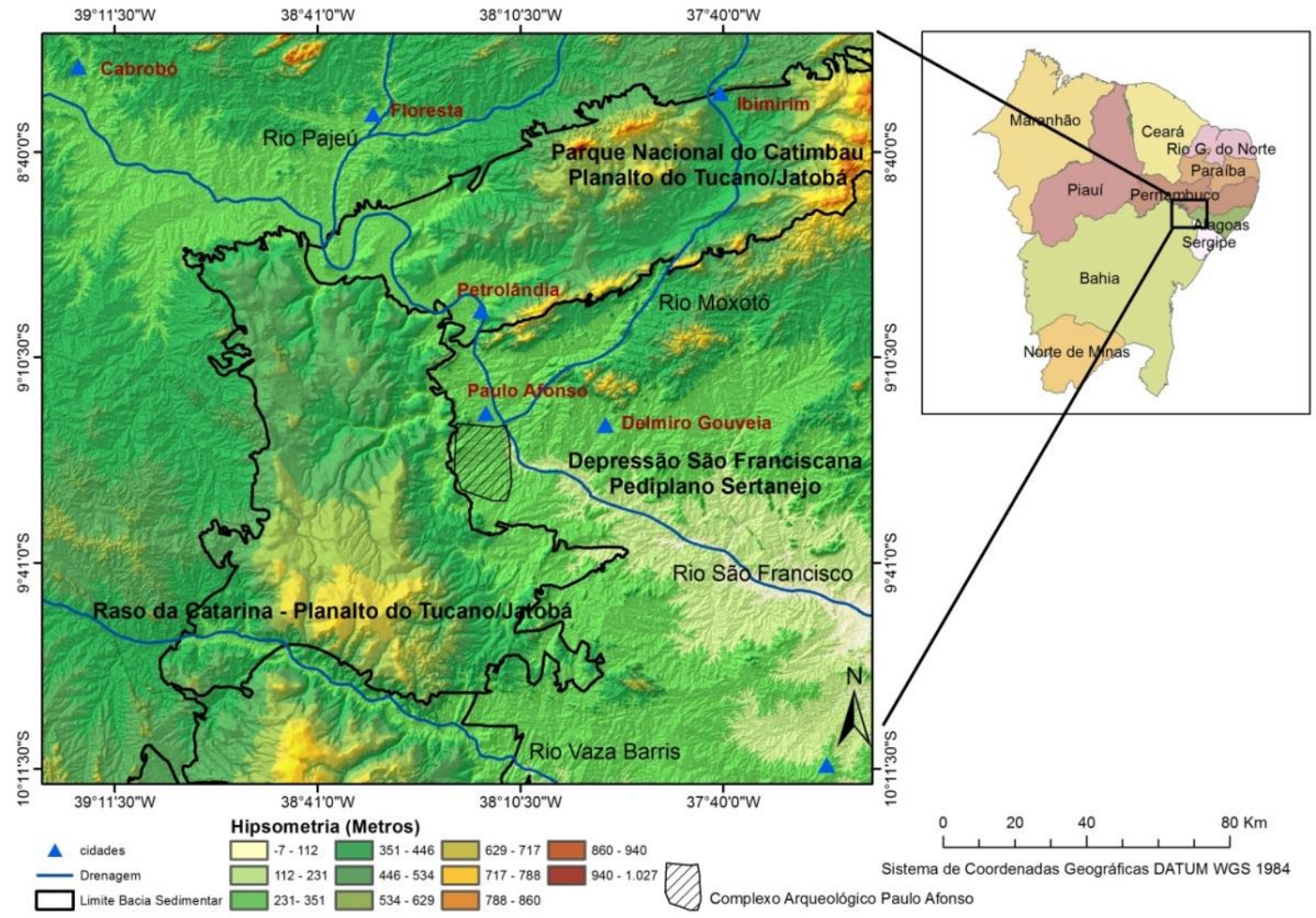

Figura 1 - Mapa de Localização do Complexo Arqueológico de Paulo Afonso

Também foi realizado um simplificado trabalho de campo na área de estudo em outubro de 2016, no qual foi realizado um levantamento fotográfico de 03 sítios arqueológicos pertencentes ao complexo (situados no povoado de Rio do Sal). Por meio deste registro, é possível ter uma noção parcial de grau de conservação e intervenção antrópica do sítio, bem como do representativo arcabouço rupestre presente no complexo, e como todo este parâmetros podem indicar as potencialidades arqueológicas geradoras de futuras pesquisas nesta região.

\section{Referencial Teórico}

O presente trabalho tem como ponto principal a análise do potencial arqueológico de uma determinada área. Este conceito reside nas reflexões sobre memória, cultura e identidade que permeiam as discussões acerca do patrimônio arqueológico. Esta atividade analítica é de extrema responsabilidade social, pois é preciso apontar os motivos pelo qual esta área é relevante e o que não pode ser simplesmente esquecido, como afirma Oliveira (2005). 
Sendo assim, de acordo com a Carta Internacional para a gestão do Patrimônio Arqueológico do Conselho Internacional de Monumentos e Sítios da UNESCO,

Está largamente reconhecido que o conhecimento e a compreensão das origens e do desenvolvimento das sociedades humanas é de fundamental importância para a identificação das suas raízes culturais e sociais. 0 património arqueológico constitui o registo básico das actividades humanas passadas. A sua protecção e a sua correcta gestão são, por isso, essenciais para permitirem aos arqueólogos e a outros estudiosos estudarem e interpretarem-nas, tendo em vista as gerações actual e futuras e o seu benefício (UNESCO-ICOMOS, 1990, p. 02).

Em se tratando da grande área arqueológica em estudo, o complexo de Paulo Afonso, há uma considerável presença de sítios arqueológicos com registro rupestre. Primeiramente, é importante conceituar, de acordo com Martin (2008) área arqueológica como divisões geográficas que compartilham de mesmas condições geoambientais e nas quais está contido um expressivo número de sítios arqueológicos, nos quais se tenha observado condições de ocupação suficientes para estudar os grupos étnicos que os habitaram.

Os sítios com grafismos rupestres são um importante arcabouço arqueológico, pois além de evidenciarem atividades humanas pré-históricas, também podem ser utilizados segundo Martin (2008), se realizado uma sistematização dos registros rupestres do Nordeste, como ferramentas para uma possível identificação e segregação dos grupos étnicos que viveram e se adaptaram às condições do interior do Nordeste, considerando a variável paleoambiental.

Pessis apud Martin (2008) considera o registro rupestre como um meio de comunicação, uma pré-escrita, desvencilhando-se dos conceitos de "arte", embora não excluindo a possibilidade dos estudos dos grafismos no contexto das ideias estéticas.

Logo, partindo do pressuposto que os registros rupestres como qualquer outro remanescente é integrante do universo cultural de um dado grupo, os mesmos compreenderiam característica ligadas ao universo simbólico, à organização social e tecnológica, à comunicação, demarcação territorial, autoafirmação da identidade étnica, dentre outras informações como discorre Vergne (2009).

Por fim, a estrutura simbólica inerente ao registro rupestre, como base na teoria apresentada, parece permear inúmeros parâmetros do contexto social desses grupos pré-históricos. Sendo assim, é possível levantar inferências sobre um importante item nas pesquisas arqueológicas, os processos de migração e ocupação de grupos humanos pretéritos.

Levando em consideração este breve embasamento teórico e o potencial da área arqueológica de Paulo Afonso, é compreensível que as representações rupestres sejam valiosas informações antropológicas e arqueológicas e a busca pela relação espacial e ambiental entre sítios e grupos humanos podem, em futura próximo, preencher partes importantes da história da ocupação do vale de São Francisco. 


\section{Metodologia}

Diante da fundamentação teórica apresentada, o presente trabalho trata-se de uma pesquisa em estágio inicial, pois com base, principalmente, em publicações recentes verifica-se que a área de estudo encontra-se atualmente submetida a uma série de pesquisas iniciais de levantamento e caracterização arqueológica.

Logo, com relação aos procedimentos metodológicos, em um primeiro momento foi realizada uma revisão de literatura e levantamento bibliográfico de estudos arqueológicos e históricos, pesquisas etnográficas sobre grupos indígenas, bem como relatórios e publicações referentes ao contexto geoambiental da região. Em conjunto estas informações permitem dá início a uma análise preliminar do estado de conservação, da caracterização arqueológica da área e dos processos relacionais entre o ambiente e os grupos humanos pré-históricos que lá habitavam isto baseado em evidências arqueológicas já discutidas neste trabalho.

Neste contexto, estas informações, de fato, são muito importantes para realizar uma análise prévia dos parâmetros arqueológicos potencializadores da grande área arqueológica de Paulo Afonso, Bahia.

É pertinente ressaltar que o que se entende como potencial arqueológico neste trabalho, diante dos preceitos de patrimônio arqueológico, é o levantamento quantitativo e qualitativo de elementos presentes na área arqueológica em estudo (ocorrência de sítios rupestres, por exemplo) que a partir de pesquisas mais extensas permitam, futuramente, gerar subsídios que possam preencher lacunas no exercício de compreensão dos processos de ocupação dos povos pré-históricos na região do vale de São Francisco.

Por fim, também foi realizado um trabalho de campo preliminar na área de estudo em outubro de 2016, com o intuito de efetuar um reconhecimento geoambiental do entorno e, consequentemente, foi realizado um levantamento fotográfico de três (03) sítios arqueológicos pertencentes ao complexo (Povoado Rio do Sal, especificamente). Por meio deste registro, é possível ter uma noção parcial de grau de conservação e intervenção antrópica do sítio, bem como do representativo arcabouço rupestre presente na área arqueológica, e como todo este parâmetros podem indicar as potencialidades arqueológicas geradoras de futuras pesquisas nesta região.

\section{Contexto Geoambiental do Vale do São Francisco: Sistemas Atmosféricos Atuantes, Aspectos Vegetais e Pedológicos.}

De fato, é importante salientar um levantamento dos elementos caracterizadores ambientais do vale do São Francisco unidos a um rico arcabouço arqueológico (sítios de pintura rupestre) em contexto, torna-se viável a compreensão do uso e processos de ocupação do pediplano sertanejo e áreas de terraços fluviais na pré-história.

O clima na área é quente e seco com chuvas de Janeiro a maio e precipitação média de 600 $\mathrm{mm}$ anuais, a média de temperatura fica em torno dos $25^{\circ} \mathrm{C}$. Em conjunto, essas são condições 
básicas que refletem o clima semiárido da região do Vale do São Francisco (CHESF/ENGE-RIO, 1993).

Devido à irregularidade espacial e temporal do regime de chuvas do semiárido, influenciada pelos vários sistemas atmosféricos de diferentes escalas ${ }^{2}$, além da variação sazonal, há também flutuações interanuais do semiárido, que acarretam em fenômenos extremos como as secas severas que podem durar anos, ou enchentes, estas últimas como resposta aos eventos pluviométricos de grande magnitude e baixa recorrência (CHESF/ENGE-RIO, 1993).

Com relação aos aspectos vegetacionais da área pesquisada, a mesma está situada no bioma caatinga, que se trata de uma porção caracterizada por caatingas de porte arbóreo e arbustivo (Figuras 2 e 3). A vegetação típica do semiárido está condicionada a sazonalidade climática da região, que perdem suas folhas na estação mais seca e com a presença de herbáceas e plantas espinhosas que se desenvolvem de forma vigorosa no período de chuvas. Assim o tipo de caatinga que se faz presente na região da depressão sanfranciscana é do tipo Caatinga hiperxerófila com setores rebaixados que apresentam adensamento vegetacional com presença das craibeiras (tabelius caraiba) de porte arbóreo. Já as espécies de menor porte estão dispostas de forma ramificada e sofrem diversas intervenções antrópicas. $O$ estrato arbustivo é bem irregular, com presença de cactáceas (como o xique-xique e o mandacarú), e arbustos como a catingueira e a jurema-preta (CHESF/ENGE-RIO, 1993
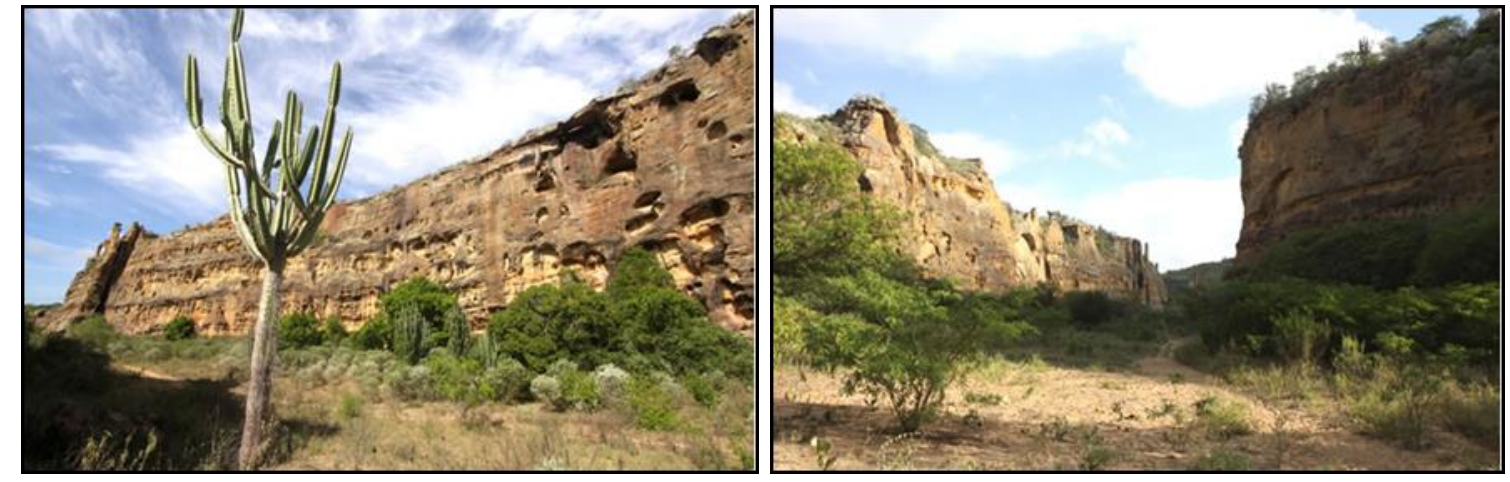

Figuras 02 e 03: Aspectos vegetacionais do vale do São Francisco. Raso da Catarina, BA. Fonte: http://www.pauloafonso.ba.gov.br/turismo/internas/atrativos/?id=32 (2016).

Quanto à pedologia local, no geral a vegetação se faz presente sobre uma cobertura pedológica delgada, assim sendo, rasa e de baixa absorção que são bastante suscetíveis a consideráveis processos erosivos ${ }^{3}$ (CHESF/ENGE-RIO, 1993). Alguns tipos de solo estão associados à presença de sais em sua composição, e isso é afetado diretamente pela própria condição climática semiárida marcada pela baixa pluviosidade fazendo com que essas coberturas acumulem sais nos seus perfis.

\footnotetext{
2 Destacam-se os Vórtices Ciclônicos de Ar Superior (VCAS), os Complexos convectivos de mesoescala (CCM), Zona de Convergência Intertropical (ZCIT), Linha de instabilidade (BARRY; CHORLEY, 2013).

${ }^{3}$ Solos do tipo neossolos litólicos, com manchas de luvissolos crômicos de maior fertilidade e planossolos (CUNHA, GUERRA, 2006).
} 


\section{a) Contexto Geoambiental do Complexo de Sítios Arqueológicos de Paulo Afonso.}

O complexo de sítios de Paulo Afonso está localizado na mesorregião do Vale do São Francisco na Bahia e no município de Paulo Afonso. O conjunto de sítios aqui abordado está situado em um contexto geológico de rocha cristalina, mais precisamente a suíte intrusiva peraluminosa Xingó de idade Neoproterozóica. Este conjunto é composto de vários tipos de formações graníticas. Nas porções a oeste do complexo se fazem presente os arenitos da Formação Marizal de idade Cretácea. Já os sítios do complexo estão em sua grande maioria localizados nos campos de granito da suíte de Xingó (CHESF/ENGE-RIO, 1993).

Os sítios no suporte rochoso utilizados pelo homem pré-histórico são formados a partir do próprio intemperismo físico e químico do granito, sendo sujeitos ao desgaste do granito (Figura 4). Essa esfoliação é marcada por feições arredondadas (matacões), apresentando um caráter esferoidal, que sofre um "descascamento", acarretando num aspecto de blocos rochosos arredondados (CHESF/ENGE-RIO, 1993).

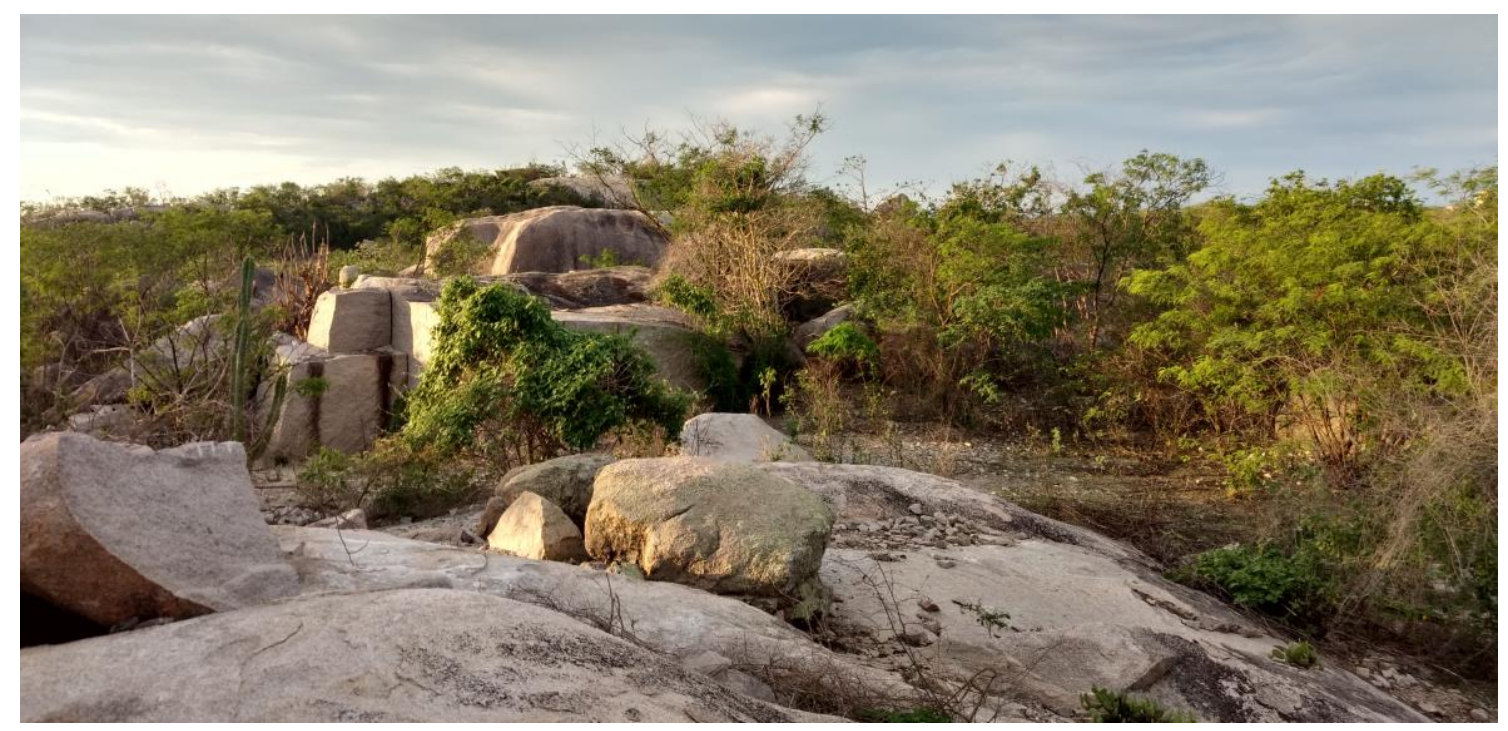

Figura 4: Campo de granito (matacões), Paulo Afonso-BA. Foto: Bruno Tavares, 2017.

Do ponto de vista geomorfológico, a litologia cristalina presente na área responde por formas aplainadas do tipo pedimentos, ou o chamado pediplano sertanejo. Essas unidades se portam na paisagem como extensos pedimentos que possuem caimento para a calha do rio São Francisco. As formas estruturadas em rochas metamórficas e ígneas estão em uma superfície de 200 a 250 m de altitude, constituindo a chamada depressão São Franciscana (Vergne; Marques, 2009).

Os setores elevados mais próximos da área respondem pelo Planalto sedimentar soerguido da bacia do Tucano-Jatobá. Estes compartimentos atingem patamares de até 500 a $550 \mathrm{~m}$ de altitude e compõem relevo caracterizado por uma superfície rígida arenítica no topo do modelado. Já os baixios e vales dos principais canais tributários do rio São Francisco respondem pela sedimentação Quaternária na área, o material sedimentar está limitado ao 
leito dos rios que apresentam pequenos bolsões de depósitos arenosos (CHESF/ENGE-RIO, 1993).

Com relação à vegetação, esta é constituída essencialmente por árvores e arbustos que perdem as folhas durante a estação seca e por plantas espinhosas e herbáceas que se desenvolvem bem no período de chuvas. Sendo uma caatinga extremamente heterogênea quanto à fisionomia e estrutura, mas em uniformidade no que se trata de sua composição florística (CHESF/ENGE-RIO, 1993).

Apesar de ser uma caatinga marcada por ser hirpexerófita, destacam-se também enclaves em ambientes mais úmidos. E nessas manchas pode-se observar a presença principalmente de sítios rupestres (Vergne; Marques, 2009).

b. O ambiente Quaternário na depressão do São Francisco: ocupações pré-históricas no vale do São Francisco.

As mudanças paleoclimáticas representam variações no conjunto de parâmetros meteorológicos pretéritos (temperaturas, ventos e índices pluviométricos), que caracterizam os estados médios típicos da superfície terrestre. Essas mudanças processam-se em escalas espaciais mundiais, regionais e locais e também temporais, tais como centenas de milhões de anos até algumas dezenas de anos. Os objetivos dos estudos paleoclimáticos são semelhantes aos climáticos, pois visam compreender as mudanças ocorridas através dos tempos geológicos no sistema constituído pela atmosfera, hidrosfera e criosfera (Suguio, 2001).

Mas por que o Quaternário? Porque se trata de um importante limite de tempo geológico (Pleistoceno, mais especificamente) palco do início dos paleoclimas glaciais formadores de grandes extensões da Terra, do ambiente biológico em geral e a própria espécie humana e sua relação vital com o ambiente em seu entorno.

Infelizmente, ainda existem poucos estudos acerca de ambientes paleoclimáticos no Brasil, principalmente na região Nordeste. Acredita-se que há uma série de dificuldades em tais pesquisas, devido ao fato de escassez e falta de continuidade das informações que dificultam as correlações cronológicas e interpretativas e por outro lado, também, pelas informações paleoclimáticas sofrerem registros por meio de medidas indiretas e, às vezes, não muito precisas.

Contudo, algumas pesquisas investigam o processo de reconstrução paleoambiental do país. Um exemplo é o estudo de paleoclima realizado no Parque nacional Serra da Capivara que demonstraram que há cerca de 9.000 a 8.000 anos AP naquela área existiram riachos, rios caudalosos e torrentes próximos aos abrigos rochosos que acolheram os homens préhistóricos e que hoje estão situados no meio da caatinga seca. O clima era tropical úmido. Foi também ponto de encontro entre dois tipos de vegetação: a Amazônica e a Mata Atlântica. Rios volumosos corriam pelos desfiladeiros despejando sua vazão sobre a planície que hoje faz parte do território habitável da população atual. Assim, antes do início do processo de transformação climática, as áreas disponíveis para habitação humana naquela região eram as terras altas do planalto e os terraços fluviais (Martin; Pessis, 2013). 
Esta situação descrita do paleoambiente piauiense é bastante semelhante a algumas conjecturas feitas sobre o ambiente de ocupação pré-histórica no vale do São Francisco com base em alguns estudos geológicos pontuais e correlações destes com as deposições estratigráficas que evidenciaram ocupação humana em pontos no entorno da bacia são franciscana.

Logo, pensando que o Quaternário é um período geológico de ótimo climático, consequentemente, segundo Pacheco e Romero (2011), surge o pressuposto de forrageamento ótimo que se trata do estabelecimento de áreas para a captação de recursos alimentares e estabelecimento de padrões de mobilidade e subsistência desses grupos humanos pretéritos.

De acordo com Guidon et al apud Martin e Pessis (2013) e Parenti (2001), em torno de 10.000 anos atrás o semiárido nordestino já estava ocupado por grupos humanos caçadores coletores diversificados e de grande mobilidade, uma vez que circundavam áreas entre planaltos, zonas fluviais e lacustres da região. Contudo, é interessante notar que somente há apenas 9.000 anos atrás é que tais áreas iniciaram seus processos de desertificação ocorridos após um intenso período de chuvas ao final do Pleistoceno, ou seja, milênios após as primeiras levas de seres humanos na área. Logo, em um clima totalmente diverso do atual, esses primeiros grupos, também designados como paleoíndios, viveram e se desenvolveram numa paisagem tropical úmida mais semelhante à região amazônica do que ao semiárido atual.

Quem escreve ou se refere à região semiárida do Nordeste do Brasil nos tempos atuais está implicitamente falando de uma paisagem majoritariamente seca, com o predomínio da caatinga, sujeita a grandes e periódicas estiagens, onde a vida é particularmente dura para os seres humanos. A descrição dos sertões nordestinos, em ensaios e trabalhos científicos, vem acompanhada de uma visão, quase sempre negativa, não raro trágica, da paisagem local [...]. Essas descrições [...] nada têm a ver com a paisagem que observaram e desfrutaram os primeiros homens que pisaram no solo do imenso território quase um milhão de $\mathrm{km}^{2}$, que hoje compreende o semiárido do Nordeste brasileiro (Martin, Pessis, 2013: 10).

De acordo com Martin (2008), as vias mais antigas de povoamento na pré-história do Nordeste ainda são desconhecidas, devido ao atual estado do conhecimento que não permite afirmar com bases científicas seguras, entretanto, os primeiros indícios parecem indicar que as terras altas, como as bacias do São Francisco, por exemplo, pontos propícios para tais eventos.

Atualmente, o rio São Francisco é considerado um importante veio fluvial do Nordeste, pois cruza as terras semiáridas da região e ainda oferece subsídios a pescadores, caçadores e agricultores que vivem em seu entorno. O rio corta os estados da Bahia, Pernambuco, Alagoas e Sergipe, tendo sua nascente situada em Minas Gerais. Segundo Martin e Pessis (2013), essa grande bacia foi centro de atração e caminho natural de grupos indígenas pré-históricos que se instalaram em abrigos rochosos pouco profundos e terraços próximos ao rio. Formavam pequenos bandos que se deslocavam e acampavam temporariamente em áreas próximas ao rio, além de prepararem seus artefatos para caçar e pescar. 
Alguns projetos de resgate e pesquisa arqueológicos ${ }^{4}$ realizados na região do vale do São Francisco realizados nas últimas décadas, hoje, permitiram o conhecimento de uma importante parte dos processos de ocupação pré-histórica da bacia são franciscana.

Assim, projetos como o Projeto Sobradinho, coordenado por Calderón (UFBA) na década de 1970, o qual identificou além de evidências artefatuais (material lítico e cerâmico), significativos sítios pré-históricos com grafismos rupestres na região que abrangeu os municípios baianos de Casa Nova, Remanso, Pilão Arcado, Barra e Juazeiro, Sento Sé e XiqueXique. O Projeto Serra Geral que ocorreu entre os estados de GO e BA, o qual foi iniciado por Pedro Inácio Schmitz e seguido por outros pesquisadores, registrou ocupações humanas de épocas pleistocênicas em sítios de abrigo e abertos pré-cerâmicos e cerâmicos, bem como sítios com pinturas rupestres chegando a datações em torno de 5.000 a 26.000 anos AP. Já o Projeto Central iniciado na década de 80 por Beltrão, ocorreu na depressão franciscana no Estado da Bahia (municípios de Central, Irecê e Xique-Xique) e proporcionou o levantamento de centenas de abrigos e grutas cobertos por pinturas rupestres com cronologias que datavam do Pleistoceno médio que forneceram datações em torno de 2.000 a 22.000 anos AP. Com relação ao Projeto Itaparica, o qual ocorreu durante a década de 80 entre os estado da Bahia e Pernambuco, identificaram um panorama de ocupação humana pré-histórica em assentamentos do tipo abertos e abrigos. Esta foi uma área bastante rica em achados, uma vez que foram evidenciados vestígios de grupos ceramistas e agricultores, sítios rupestres, bem como aldeamentos missionários franciscanos e jesuítas. Tal pesquisa trouxe a luz o emblemático sítio Gruta do Padre (Petrolândia-PE) que abarcava uma significativa quantidade de artefatos líticos lascados e foi utilizado como uma necrópole, abrangendo datações de 2.000 a 7.000 anos AP (MARTIN, 2008). E por fim, o Projeto Xingó cuja principal responsável é a arqueóloga Cleonice Vergne, gerou o levantamento de vários sítios arqueológicos do tipo a céu aberto e de registro rupestre, muitos deles associados a artefatos líticos, cerâmico, ósseos, dentre outros que alcançam datações de cerca de 9.000 anos AP (Marques, 2008).

Em um contexto geral, é notável que em função de parâmetros climáticos e sazonais, os grupos pré-históricos do vale de São Francisco estariam, evidentemente, estavam adaptados às condições ambientais da época e possuíam suas estratégias de mobilidade e subsistência condizentes aos recursos geoecológicos da região. Evidências estas que podem ser facilmente representadas pelo quantitativo de sítios arqueológicos registrados na área em estudo.

\section{c. O potencial arqueológico do Complexo Arqueológico de Paulo Afonso, Bahia.}

Primeiramente, é importante ressaltar que a região do vale de São Francisco, com base no que já foi previamente discutido neste trabalho, há muito se apresenta a partir de dados históricos e arqueológicos como uma área recorrente de processos de ocupação pré-histórica de povos indígenas e, consequentemente, a vinda de colonizadores e grupos de missões com o intuito de desbravar e conquistar esta área inóspita seguindo o ideal de defesa do território nacional

\footnotetext{
${ }^{4}$ Denominados Sobradinho, Serra Geral, Central, Itaparica e Xingó (Martin; Pessis, 2013).
} 
(diante de ameaças de invasão de outras nações), porém promissora, sobretudo no que diz respeito aos recursos naturais do vale (hídricos, principalmente).

A grande bacia do São Francisco foi um centro de atração e caminho natural de grupos pré-históricos desde os fins do pleistoceno. A partir dos relatos dos missioneiros, aventureiros e viajantes que se adrentaram nos sertões do São Francisco, desde os começos da colonização, temos informações dos habitantes indígenas do grande vale, da sua resistência e seu paulatino extermínio ou fuga a lugares quase inacessíveis nas serras circundantes. $\mathrm{Na}$ atualidade, os Pankararú, Atikum, Kimbiwá na margem pernambucana, os truká da ilha da Assunção e os Kiriri, Tuxá e Pankararé, na Bahia, são remanescentes daquelas populações que, em levas sucessivas, foram ocupando o médio e baixo vale são franciscano a partir do oitavo milênio a. C. (Martin, 1998, p. 09).

Ainda hoje, é possível ver o quanto o rio São Francisco e o seu contexto geoambiental é importante para as atividades de irrigação e geração de energia da região Nordeste. Entretanto, no município de Paulo Afonso, mais precisamente, o vale são franciscano contém um grande potencial arqueológico resguardado nos vários sítios rupestres já identificados, e hoje pertencentes à área arqueológica de Paulo Afonso.

O complexo arqueológico em questão, segundo pesquisas mais recentes desenvolvidas por Vergne e Marques (2009) apontam uma considerável presença de sítios arqueológicos com registro rupestre localizados em áreas próximas aos terraços de rio e do tipo céu aberto, uma vez que a maior parte encontra-se nos notórios campos de arenitos ou matacões, feições estas tão comuns no médio vale de São Francisco.

De acordo com Vergne e Marques (2009) a história das pesquisas na área Paulo Afonso teve início na década de 90 após uma paralisação na construção de hidrelétrica e o estabelecimento de um novo convênio entre a CHESF (Cia. Hidrelétrica do São Francisco), a Petrobrás e a UFS (Universidade Federal do Sergipe) onde são prospectados platôs, terraços, paredões e abrigos na região de abrangência de impactos das barragens. Neste momento, novos sítios rupestres são encontrados na Bahia e Sergipe.

Nessas pesquisas, ainda de acordo com Vergne e Marques (2009), comprova-se que grupos humanos pré-históricos da região ocuparam praias e terraços do rio de forma intensa e que os painéis pictóricos desta região são quase que exclusivamente compostos por grafismos puros, e raras são as representações zoomorfas e antropomorfas, assim como a sobreposição de pinturas.

Logo, uma peculiaridade notória é que o registro rupestre da área de Paulo Afonso possui um estilo gráfico que não se enquadra nas descrições das tradições Nordeste ${ }^{5}$ e Agreste $^{6}$, tão comuns na região do vale.

5 Identificável pela riqueza de figuras antropomorfas e zoomorfas, geralmente, inseridas em cenas de sexo, luta, caça, entre outras. Há uma predominância da cor vermelha em diversas tonalidades. (Martin, 2008; Prous, 2006). 
Não se conhece, em toda a América, uma área arqueológica com a densidade de abrigos sob rocha pintados como a do Parque Nacional Serra da Capivara, seguido da região do Seridó e da Chapada Diamantina, somente para citar as três áreas mais densamente pesquisadas nas últimas décadas. Mas, também, outras regiões estão se revelando promissoras a partir de pesquisas recentes no semiárido de Pernambuco [...] registraram-se duas centenas de sítios com pinturas e gravuras que em grande parte encontram-se situadas na depressão sanfranciscana (Martin; Pessis, 2013, p. 24).

Com relação a estes dados apresentados, os estudos mostram uma relevante importância dessa região para o conhecimento dos padrões de assentamento e ocupação de grupos préhistóricos no vale do São Francisco, gerando um evidente potencial para o entendimento da ocupação humana no Nordeste e na América.

O estudo desenvolvido por Vergne e Marques (2009), constatou que há mais de 50 anos o complexo arqueológico de Paulo Afonso ${ }^{7}$ e todo seu arcabouço de sítios com registro rupestre sofre com a desenfreada exploração de rochas para utilização em pavimentação, construção civil e demais atividades, inclusive pelo Poder Público, o qual é responsável pela proteção desse patrimônio.

Apesar de em 2004 o IBAMA ter fechado as pedreiras, Vergne e Marques (2009) afirmam que começa um grande impasse entre a preservação dos sítios, a sobrevivência das famílias e o papel dos órgãos públicos e privados. Até o momento pouca coisa foi alcançada para resolver esta problemática e que embora muitas alternativas tenham sido discutidas acerca da salvaguarda desse patrimônio, pouco se pode fazer quando não há pouca inciativa e parceria de instituições públicas e privadas com instituições de pesquisas competentes.

Tendo em vista isso, foram detectados na área arqueológica de Paulo Afonso, Bahia, 48 sítios destruídos e 64 sítios rupestres intactos localizados numa região do vale do São Francisco em foi utilizada como local de assentamento de populações de caçadores-coletores que estavam em busca de sobrevivência por meio dos peixes, da água, da caça e de todo os recursos vitais que a proximidade com o rio São Francisco e seu entorno proporcionavam (Vergne; Marques, 2009) (Figura 5).

\footnotetext{
6 Presença de grafismos puros simples ou muito elaborados acompanhados por grafismos de ação; grafismos de grande tamanho (antropomorfo e zoomorfo), geralmente isolados, sem formar cenas, e estas quando presentes são compostas por poucos indivíduos e animais. Geralmente, os grafismos possuem aspecto estático e isolado, assemelhando-se a uma figura totêmica. Marcas de mão também são identificadas (carimbos) e quanto à pigmentação, o vermelho também é predominante (Martins, 2008).

7 Abrange os povoados do Rio do Sal, Lagoa das Pedras, Mão Direita e Malhada Grande, na Bahia. Porém, somente a área arqueológica de Malhada Grande é objeto do presente estudo.
} 

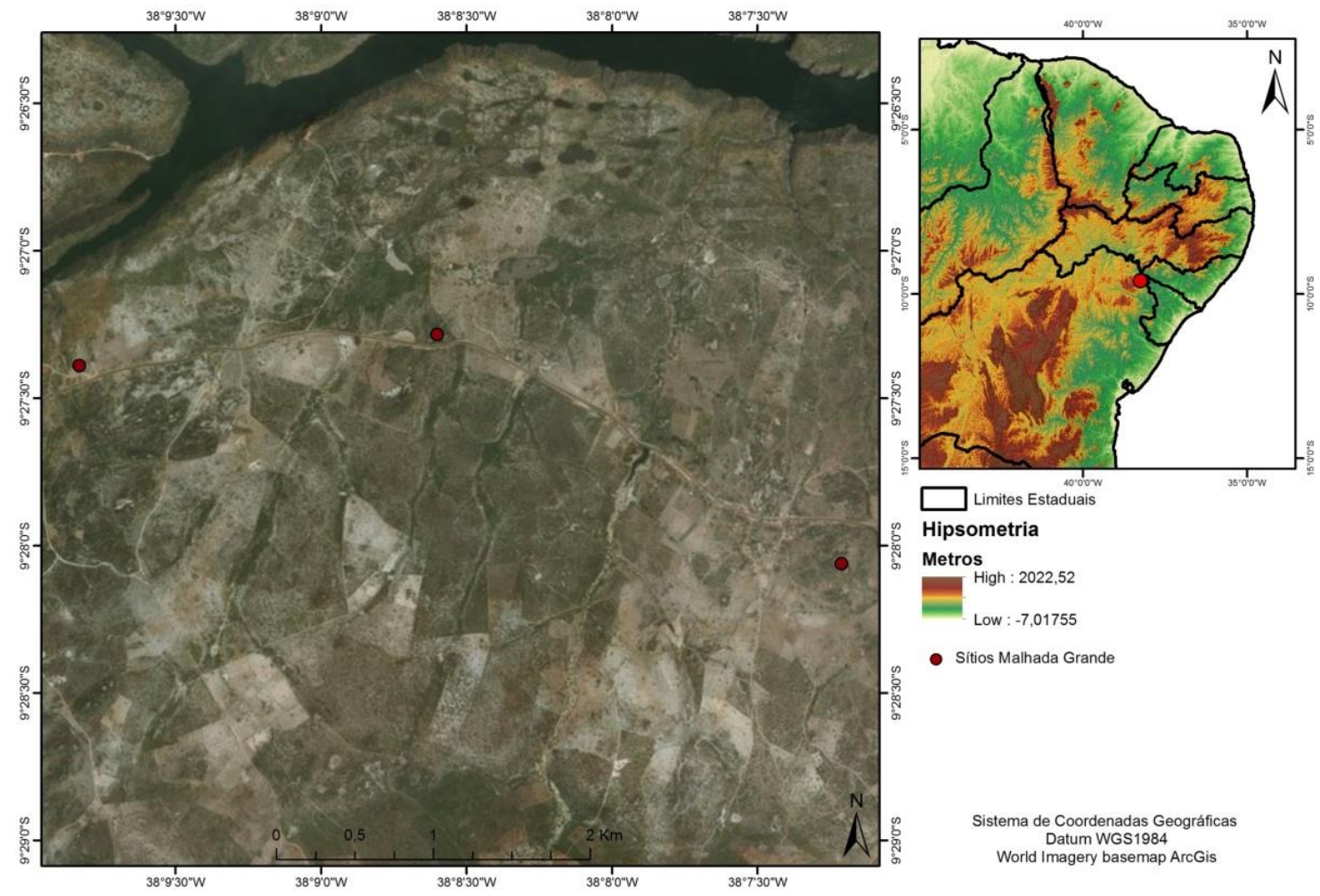

Figura 5: Localização dos Sítios Arqueológicos na Depressão São Franciscana.

De um modo geral, as potencialidades arqueológicas da área de Malhada Grande estão resguardadas no grande arcabouço arqueológico que a região possui (Figura, 6, 7, 8, 9, 10 e 11). Pois se tratam de sítios arqueológicos com registro rupestre que evidenciam a presença humana no passado do local, bem como suas interligações com o geoambiente altamente significativo em recursos. Dados estes quando correlacionados podem gerar estudos significativos sobre como seria o modo de vida, organização social, tecnológica e, sobretudo, cultural desses antigos povos indígenas.

Outro ponto não menos importante, é o risco atual o qual corre este patrimônio diante das ameaças extrativistas atuantes. É primordial que se pense em mais pesquisas e ações efetivas de preservação desse bem arqueológico, como uma forma de preservar também as histórias passadas e que estão por vir, considerando a busca pela compreensão dos processos de ocupação do vale de São Francisco. 

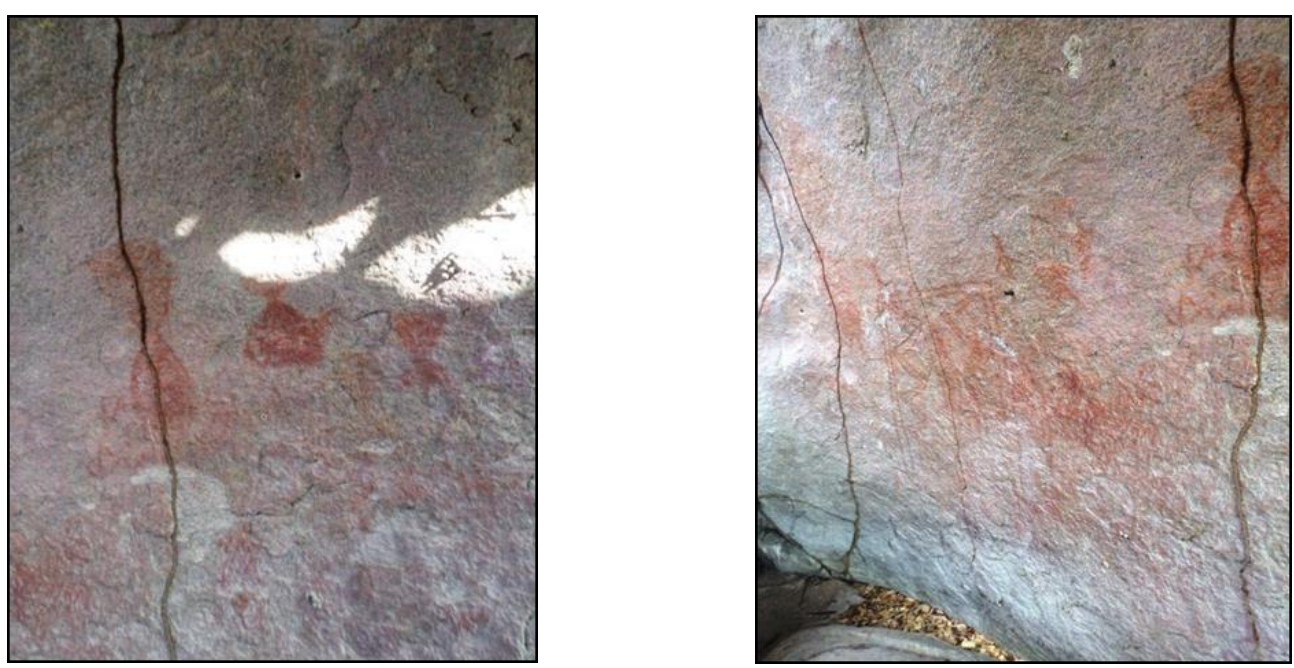

Figuras 6 e 7: Grafismos rupestres (grafismos puros e padrões geométricos), Paulo Afonso, BA. Sítio 23, segundo catalogação do CAAPA ${ }^{8}$, 2008/09/Rio do Sal. Foto: Fernanda Barbosa, 2016.
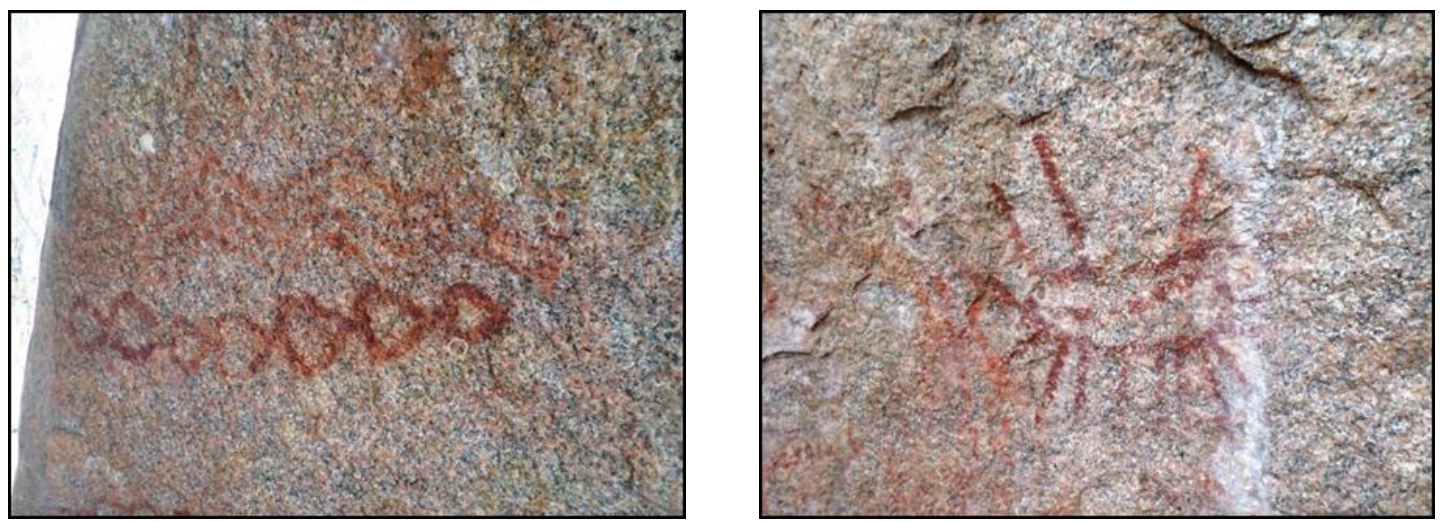

Figuras 8 e 9: Grafismos rupestres (Padrões geométricos e grafismos puros), Paulo Afonso, BA. Catalogação do CAAPA não identificada/Rio do Sal. Foto: Fernanda Barbosa, 2016.
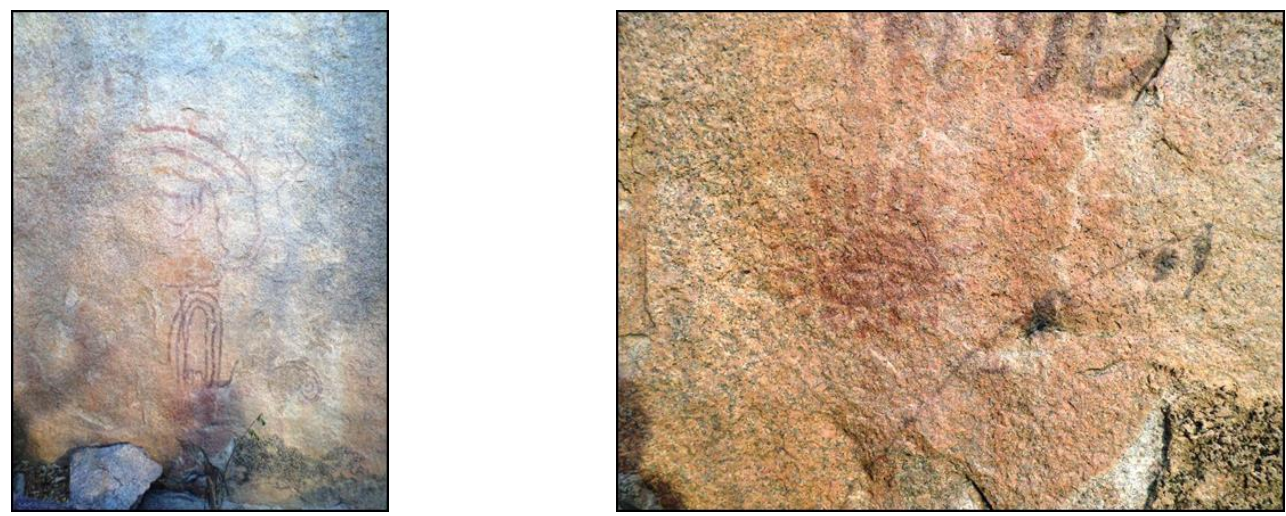

Figuras 10 e 11: Grafismos rupestres (antropomorfos e grafismos puros), Paulo Afonso, BA. Sítio CAAPA/Rio do Sal, segundo catalogação do CAAPA, 2008/09. Foto: Fernanda Barbosa, 2016.

\footnotetext{
${ }^{8}$ Centro de Arqueologia e Antropologia de Paulo Afonso (Universidade do Estado da Bahia).
} 


\section{Considerações Finais}

Retomando alguns pontos apresentados no desenvolvimento do presente trabalho, certificase que os primeiros homens que habitaram a região conhecida do vale de São Francisco, desde o final do Pleistoceno, além de estabelecerem assentamentos no local utilizaram-se dos vários recursos naturais disponíveis para sua sobrevivência. Nesse sentido, compreende-se que a região do vale sanfranciscano foi palco de grandes mobilidades de grupos humanos que habitaram o entorno daquela grande bacia hidrográfica.

Esta afirmativa apoia-se nas publicações científicas e pesquisas arqueológicas (algumas em andamento) realizadas na área há anos que evidenciaram um grande arcabouço de sítios arqueológicos com a presença de registro rupestres, artefatos produzidos pelo homem préhistórico, enterramentos e necrópoles, que em conjunto mais do que evidenciam o modo de vida cultural, social e tecnológico desses povos do passado.

No trabalho em questão, em se tratando do âmbito arqueológico, foram enfatizados os sítios com grafismo rupestres presentes na área arqueológica de Paulo Afonso, Bahia, uma vez que é uma área com enorme potencial arqueológico. Porém poucas pesquisas foram desenvolvidas acerca desta região e, portanto, iniciativas assim como a da catalogação realizada por Vergne e Marques (2009) permitem gerar subsídios para novos estudos que investigam os processos de ocupação do Nordeste e suas, ainda existentes, lacunas historiográficas.

Outro ponto que ficou evidente também é a necessidade de gerar novas pesquisas e intervenções da comunidade científica, pública e civil para a proteção deste vários sítios rupestres catalogados na área que, por hora, ainda sofrem um intenso impacto ambiental.

Logo, a pesquisa em questão não se esgota aqui. Trata-se apenas do inicio, junto com muitas outras já iniciadas e em avanço grau de desenvolvimento. Ainda assim, a partir deste estudo é possível que alguns aspectos possam ser desenvolvidos e aprofundados. Uma das principais possibilidades é fornecer subsídios para pesquisas arqueológicas com problemáticas específicas e outra é gerar uma maior atenção e envolvimento instituições acadêmicas públicas e privadas no objetivo de melhor gerir o potencial patrimônio arqueológico - que enfrentou vários dilemas socioambientais - residido no complexo arqueológico de Paulo Afonso.

\section{Referências}

BARRY, R. G.; CHORLEY, R. J. Atmosfera, tempo e clima. 9 ed. Porto Alegre: Bookman, 2013.

CHESF/ENGE-RIO. EIA-RIMA da UHE-Xingó. Tomo I e II, Diagnóstico Ambiental, meio físico, v. 2, 1993.

CUNHA, S. B., GUERRA, A. J. T. Geomorfologia do Brasil. 4 ed. Rio de Janeiro: Bertrand Brasil, 2006.

MARQUES, J. Cultura Material e Etnicidade dos Povos Indígenas da Bacia do São Francisco Afetados por Barragens: Um Estudo de Caso do Povo Tuxá de Rodelas. Salvador, 2008. Tese de Doutorado em Cultura e Sociedade (UFBA). 
MARTIN, G. O Povoado Pré-Histórico do Vale do São Francisco (Brasil). Recife: Clio Arqueológica, n. 13, 1998.

MARTIN, G. PESSIS, A. M. Breve Panorama da Pré-História do Vale do São Francisco no Nordeste do Brasil. In: Fumdhamentos, v. 1, n. 10, São Raimundo Nonato, 2013.

MARTIN, G. Pré-História do Nordeste do Brasil. 5. ed. Recife: Editora Universitária, 2008.

OLIVEIRA, A. T. D. Um Estudo em Arqueologia Urbana: A Carta de Potencial Arqueológico do Centro Histórico de Porto Alegre. Porto Alegre, 2005. Dissertação de Mestrado (PUCRS).

PACHECO, M. L. A. F.; OMERO, G. R. A apropriação do ambiente do entorno de abrigos sob rocha por grupos humanos pretéritos: implicações ecológicas e paisagísticas no estabelecimento dos padrões de mobilidade para a alocação de recursos alimentares no cerrado. Campina Grande: Revista Eletrônica do Laboratório de Arqueologia e Paleontologia da UEPB, ano 2, v. 1, 2011.

PARENTI, F. Le gisement quaternaire de la Pedra Furada (Piaui, Brésil). Stratigraphie, chronologie, évolution culturelle. Paris: Editions Recherches sur les Civilisations, v. 1. 2001.

PESSIS, A. M. Imagens da Pré-História. São Raimundo Nonato: FUMDHAM/PETROBRÁS, 2003.

PROUS, A. O Brasil antes dos brasileiros: a pré-história do nosso país. Rio de Janeiro: Zahar, 2006.

SUGUIO, K. Geologia do Quaternário e mudanças ambientais: passado+presente=future?.São Paulo: Paulo's Comunicação e Artes Gráficas, 2001.

UNESCO-ICOMOS. Carta sobre a Protecção e a Gestão Do Património Arqueológico. 1990. Trad. Por Antônio de Borja Araújo, 2006.

VERGNE, C.; MARQUES, J. Pedras pintadas: dilemas socioambientais do complexo arqueológico de Paulo Afonso. Paulo Afonso: Fonte Viva, 2009. 